Field-Effect Transistors

in Integrated Circuits 
Other titles in Electrical and Electronic Engineering

ELECTRONIC EQUIPMENT RELIABILITY: J. C. Cluley AN INTRODUCTION TO ELECTRICAL INSTRUMENTATION: $B$. A. Gregory AN INTRODUCTION TO THE ANALYSIS AND PROCESSING OF SIGNALS: Paul A. Lynn

LINEAR MICROELECTRONIC SYSTEMS: $A$. G. Martin and $F$. W. Stephenson AN INTRODUCTION TO DIGITAL LOGIC: $A$. Potton

AN INTRODUCTION TO ELECTRICAL CIRCUIT THEORY: G. Williams 


\title{
Field-Effect Transistors in Integrated Circuits
}

\author{
J. T. Wallmark \\ L. G. Carlstedt
}

Chalmers University of Technology

Gothenburg

Macmillan Education 
() J. T. Wallmark and L. G. Carlstedt 1974

() Torkel Wallmark, Gunnar Carlstedt 1971

Softcover reprint of the hardcover 1st edition 1974 978-0-333-15243-0

All rights reserved. No part of this publication may be reproduced or transmitted, in any form or by any means, without permission

First published in Great Britain by

THE MACMILLAN PRESS LTD

London and Basingstoke

Associated companies in New York Dublin

Melbourne Johannesburg and Madras

Authorised English language edition of

Fälteffekttransistorn, first published 1971 by

P. A. Norstedt \& Söners Förlag, Stockholm

SBN 333152433

ISBN 978-1-349-02055-3 ISBN 978-1-349-02053-9 (eBook)

DOI 10.1007/978-1-349-02053-9

Library of Congress catalog card no.: 73-19429 


\section{Contents}

$\begin{array}{ll}\text { Preface } & \text { ix }\end{array}$

Principal Notations $\quad x i$

Introduction 1

Origin of the Field-Effect Transistor $\quad 1$

Field-Effect Transistors: Concepts and Nomenclature 3

1 Properties of Semiconductors $\quad 6$

The crystal structure $\quad 6$

The energy band model 6

Metal, insulators, semiconductors 8

The Fermi level 9

Electrical Charges in Semiconductors $\quad 10$

Electrons and holes, intrinsic semiconductors $\quad 10$

Extrinsic (doped) semiconductors $\quad 12$

Field effect $\quad 14$

$\begin{array}{ll}\text { Properties of the surface layer } & 16\end{array}$

2 Metal Oxide Semiconductor (MOS) Field-Effect Transistors 18

The Structure of Field-Effect Transistors 18

Depletion and enhancement types $\quad 19$

Drain and source $\quad 20$

Threshold voltage and charge balance 21

Current-Voltage Characteristics 24

Very low drain voltage (the linear region) 24

Low drain voltage (the region below pinch-off) 26

High drain voltage (the saturation region) 26

Second-Order Effects in Current-Voltage Characteristics 28

The output impedance $\quad 28$

The substrate voltage $\quad 28$

Breakdown in the drain region $\quad 29$

Breakdown in the gate $\quad 29$

The effect of temperature on MOS transistors $\quad 29$

Ageing effects 31 
Capacitances of MOS Transistors $\quad 31$

The gate capacitance 31

The drain capacitance $\quad 32$

3 Special Types of Field-Effect Transistors 34

Field-Effect Transistors with $p n$ Junction Gate $\quad 34$

Current-voltage characteristics 34

Temperature dependence $\quad 37$

Capacitances $\quad 37$

Field-Effect Transistors with Schottky Gate 37

Memory Transistors $\quad 40$

4 MOS Transistors in Digital Circuits 42

General Requirements on Logic Circuits 42

The Inverter: Characteristics and Power Consumption 44

Stability of the quiescent points of the inverter 51

Noise margins and noise immunity 53

Speed of the inverter $\quad 56$

Design of the inverter 61

Summary 63

Complementary Inverters $\quad 64$

Clocked Logic $\quad 71$

5 Logic Gates $\quad 73$

NOR Gates $\quad 73$

NAND Gates $\quad 75$

Relay Logic $\quad 77$

Complementary Circuits $\quad 77$

6 Registers and Memories $\quad 81$

Flip-Flop Circuits $\quad 81$

Dynamic Registers 84

Shift Registers $\quad 85$

Dynamic shift registers $\quad 85$

Static shift registers $\quad 87$

Charge-Coupled Devices and Bucket-Brigade Registers 93

Charge-coupled devices 93

Bucket-brigade registers $\quad 94$

Random-Access Memories 95

Read-only memories $\quad 95$

Read-write memories $\quad 100$

7 MOS Transistors in Linear Circuits $\quad 110$

Characteristic Curves of MOS Transistors 110

Leakage Currents 111

Small-Signal Circuits for Earthed Emitter 111

Noise in MOS Transistors 115 
8 Processing and Technology 119

Single-Crystal Material 119

Slicing and Surface Treatment 119

Oxidation of Silicon 123

$\begin{array}{lr}\text { Photoresist } & 126\end{array}$

Mask Fabrication $\quad 127$

Diffusion $\quad 127$

Clean Oxide for the Gate Insulator $\quad 128$

Metallisation 130

Thin-Film Transistors 130

Silicon-on-Sapphire Technique 131

9 Integrated Circuit Technology 135

Silicon Surface Area 135

Crossover Connections 136

Protection against Static Breakdown 137

Layout of MOS Circuits 137

Test Units 139

Large-Scale Integration 139

Interfacing Considerations for Integrated Circuits $\quad 141$

Practical example of an MOS LSI circuit $\quad 145$

$\begin{array}{lr}\text { Bibliography } & 150\end{array}$

$\begin{array}{ll}\text { Index } & 151\end{array}$ 


\section{Preface}

Interest in field-effect transistors has been spurred by two new solid state electronic developments-large-scale integrated circuits (LSI) and semiconductor memories. The fact that field-effect transistors can be made smaller and less power consuming than conventional bipolar units explains their much faster growth, particularly in these areas. At present about 20 per cent of all transistors are of the field-effect type and this percentage is expected to grow to about 40 per cent in five years.

This book has a wide scope-from semiconductor physics to the design of large-scale integrated circuits. To encompass such a large field in a small volume it has been necessary to concentrate on essentials. For this reason analytical derivations have generally been omitted and straightforward expressions given, justified only by physical reasoning. It is believed that this is more useful to the circuit designer who may not be interested in the detailed evolution of the expressions but who needs to know and use them in order properly to design his circuits and to understand the limitations and trade-offs that are available. The equipment designer on the other hand, may be helped by a condensed compilation of the essentials of circuit design with field-effect transistors.

Field-effect transistors are used mainly in digital circuits and only fractionally in analogue circuits. For this reason this book strongly emphasises digital applications. However, a brief treatment of the essentials of analogue circuits is included for completeness.

The book starts with a short summary of the field-effect transistor to introduce the terminology and functions of the main components. It provides a form of abstract, just as all scientific papers are provided with an abstract, to help people in a hurry to find out what it is all about. Next follows a brief note on the history of the device.

Chapter 1 gives a short review of semiconductor physics in just enough detail to make it possible to understand the field-effect transistor and its performance, limitations and some of the adjustments needed between parameters such as speed, power, reliability, cost, life, and so on. This chapter is optional reading.

Chapter 2 describes the most important type of field-effect transistor, the metal oxide semiconductor (MOS) transistor, and gives details of its structure and performance. Some important special versions of the field-effect transistor other than the MOS are given in chapter 3, the pn junction gate field-effect transistor (JFET), the Schottky gate field-effect transistor and the MNOS memory transistor. Also included are the recent newcomers to the field-charge-coupled devices and bucket-brigade registers.

Chapters 4-7 treat on the use of field-effect transistors in different circuits with 
special emphasis on integrated circuits. The basic building block for these is the inverter, which is discussed in chapter 4 . The use of inverters in digital logic circuits is to be found in chapter 5 . The most important application for field-effect transistors is in memory circuits, which are treated in chapter 6 starting with their main building block, the flip-flop circuit, proceeding through registers to very complex and large random-access memories (RAM) and read-only memories (ROM). However, there are also some important applications of field-effect transistors in linear circuits, which are examined in chapter 7.

What can be done with field-effect transistors, and just as important, what cannot be done, depends to a large extent on technological factors. Because of the widespread use of integrated circuits in modern electronic systems it has become necessary for the circuit designer to know at least the essentials of circuit and component processing in order to arrive at the best circuit design from among the many possibilities. The technology of devices and integrated circuits is given in chapter 8, while the special considerations that refer to MSI medium scale integration (12-100 stages) and LSI large-scale integration ( $>100$ stages), have been summarised in chapter 9.

For assistance with the translation the authors are grateful to Mr S. S. Shivaraman. They would also like to thank the Intel Corporation of Santa Clara, California for permission to include the examples of FET junctions shown in figures 6.13 and 6.37 and the practical example of a MOS LSI circuit described in detail in chapter 9.

J. T. Wallmark

L. G. Carlstedt 


\section{Principal Notations}

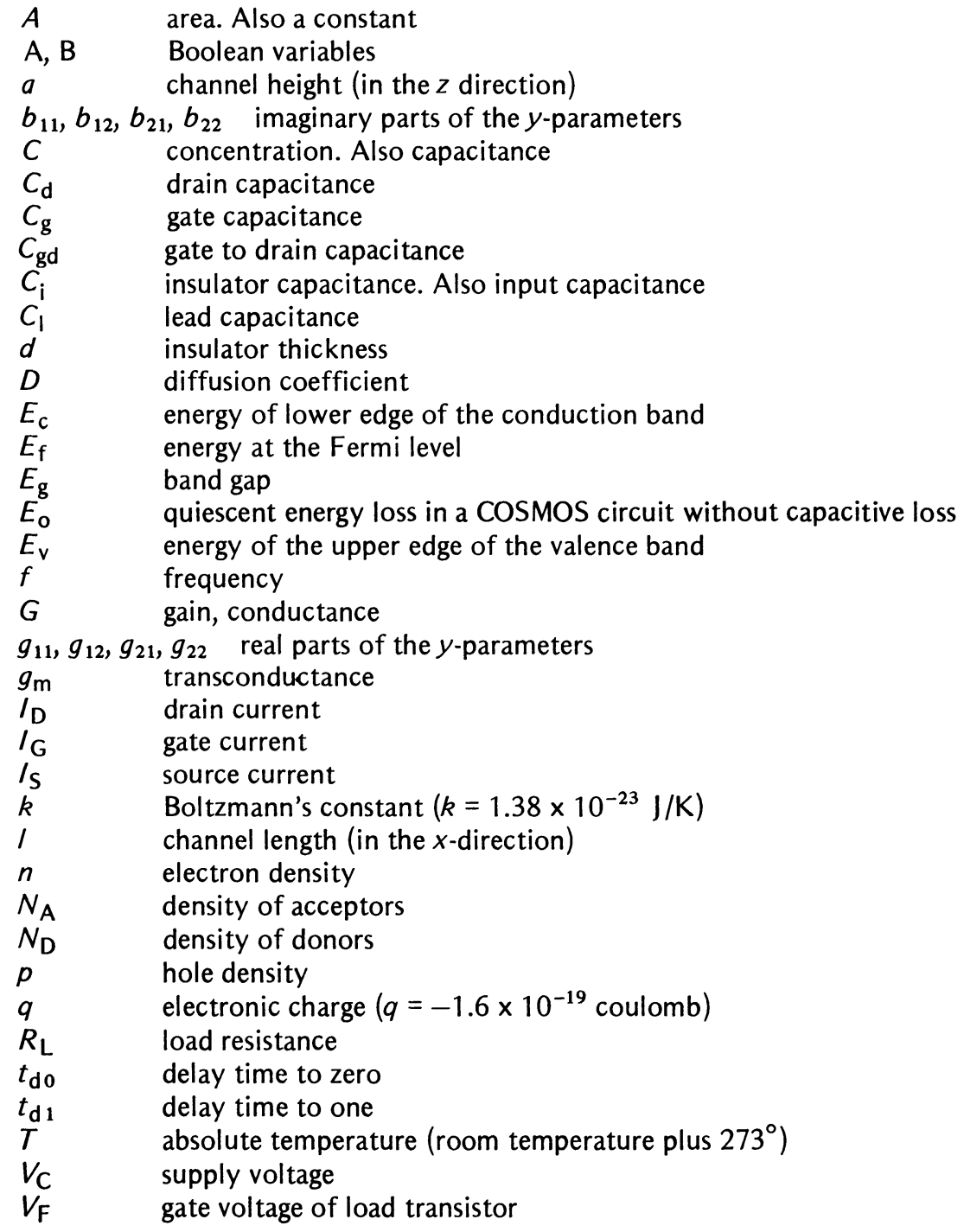




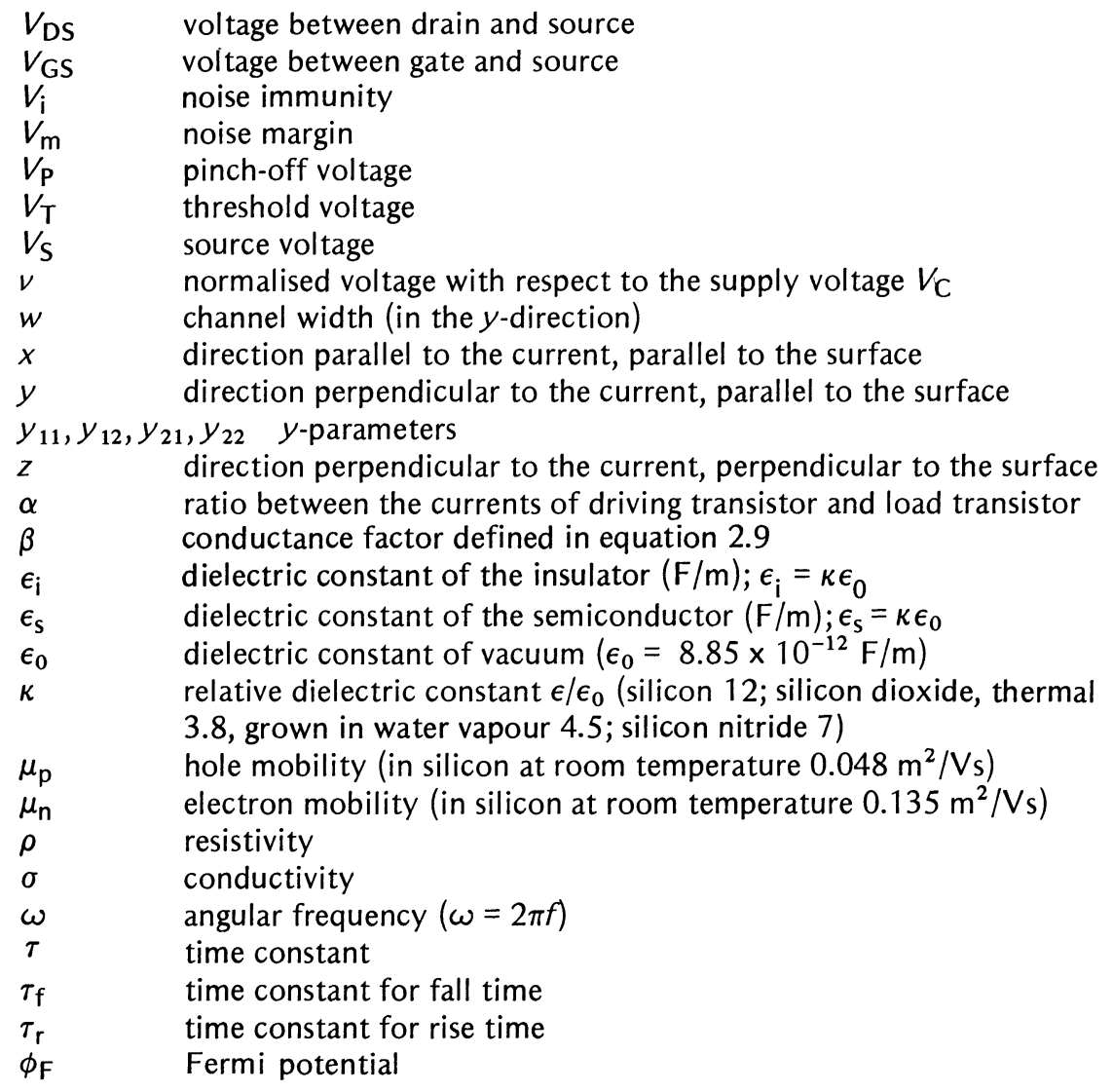

